\title{
STABLE HYDROGEN PAIR TRAPPED AT CARBON IMPURITIES IN SILICON
}

\author{
B. Hourahine, ${ }^{1, *}$ R. Jones, ${ }^{1}$ S. Öberg, ${ }^{2}$ P. R. Briddon, ${ }^{3}$ V. P. Markevich, ${ }^{4}$ R. C. Newman, ${ }^{5}$ J. \\ Hermansson, ${ }^{6}$ M. Kleverman, ${ }^{6}$ J. L. Lindström, ${ }^{6}$ L. I. Murin,${ }^{7}$ N. Fukata, ${ }^{8}$ and M. Suezawa ${ }^{8}$ \\ ${ }^{1}$ School of Physics, The University of Exeter, Exeter EX4 4QL, UK \\ ${ }^{2}$ Department of Mathematics, Luleå University of Technology, S-97187 Luleå, Sweden \\ ${ }^{3}$ Department of Physics, The University of Newcastle upon Tyne, Newcastle upon Tyne NE1 7RU, UK \\ ${ }^{4}$ Centre for Electronic Materials, UMIST, Manchester M60 1QD, UK ${ }^{\dagger}$ \\ ${ }^{5}$ Centre For Electronic Materials and Devices, The Blackett Laboratory, \\ The Department of Physics, Imperial College, London SW7 2BZ, UK \\ ${ }^{6}$ Department of Physics, University of Lund, S-22100 Lund, Sweden \\ ${ }^{7}$ Institute of Solid State and Semiconductor Physics, Minsk 220072, Belarus \\ ${ }^{8}$ Institute for Materials Research, Tohoku University, Sendai 980-8577, Japan
}

(Dated: October 9, 2001)

\begin{abstract}
Local mode spectroscopy and $a b$ initio modeling are used to investigate two trigonal defects found in carbon rich $\mathrm{Si}$ into which $\mathrm{H}$ had been in-diffused. Isotopic shifts with $\mathrm{D}$ and ${ }^{13} \mathrm{C}$ are reported along with the effect of uniaxial stress. Ab-initio modeling studies suggest that the two defects are two forms of the $\mathrm{CH}_{2}^{*}$ complex where one of the two hydrogen atoms lies at an anti-bonding site attached to $\mathrm{C}$ or $\mathrm{Si}$ respectively. The two structures are nearly degenerate and possess vibrational modes in good agreement with those observed experimentally. The defects are energetically favourable in comparison with separated $\mathrm{C}_{\mathrm{s}}$ and $\mathrm{H}_{2}$ in $\mathrm{Si}$ and may represent aggregation sites for hydrogen.
\end{abstract}

PACS numbers: 61.72.-y,61.72.Ji,61.72.Bb,63.20.Pw

\section{INTRODUCTION}

Hydrogen and carbon are common interstitial and substitutional impurities respectively in silicon ${ }^{1,2}$. The single hydrogen defect is highly mobile and is easily trapped by impurities and lattice defects. One prominent defect found in proton implanted $\mathrm{Si}$, or $\mathrm{Si}$ containing $\mathrm{H}$ which has been $e$-irradiated, is the trigonal $\mathrm{H}_{2}^{*}$ center which contains two inequivalent $\mathrm{H}$ atoms. One $\mathrm{H}$ atom lies at a bond centered site and the other at a neighboring antibonding $\operatorname{site}^{3}$. It might be expected that dilated Si-Si bonds due to the strain field surrounding substitutional carbon atoms will be trapping sites for $\mathrm{H}$. However, the greater binding energy of $\mathrm{H}$ with $\mathrm{C}$ rather than $\mathrm{Si}^{4}$ suggests that $\mathrm{H}$ will attach directly to $\mathrm{C}$. Examples of defects

FIG. 1: The two degenerate $C_{3 v}$ structures for $\mathrm{CH}_{2}^{*}$. a) shows $\mathrm{SiH}_{\mathrm{bc}} \mathrm{CH}_{\mathrm{ab}}$, and b) displays $\mathrm{CH}_{\mathrm{bc}} \mathrm{SiH}_{\mathrm{ab}}$. Relevant bondlengths and angles are shown where appropriate.
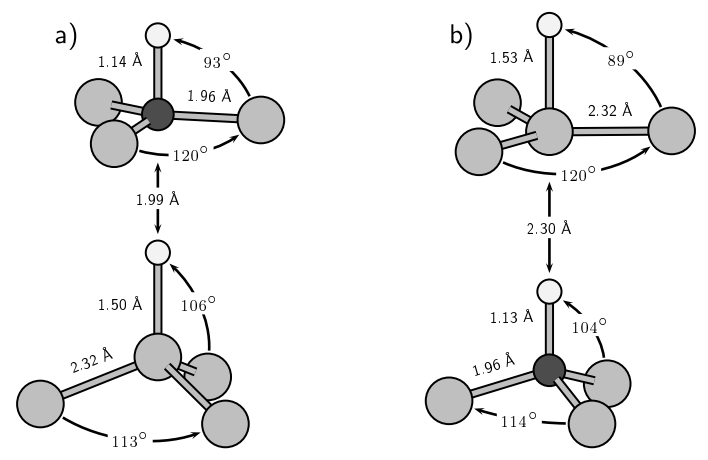

FIG. 2: a) Difference absorption spectra measured at $10 \mathrm{~K}$ with a resolution $0.5 \mathrm{~cm}^{-1}$ for 1 ) a $\mathrm{Si}:{ }^{12} \mathrm{C}$ sample doped with hydrogen and 2) a $\mathrm{Si}^{13} \mathrm{C}$ sample doped with hydrogen (spectra of a Si: ${ }^{12} \mathrm{C}$ sample and a $\mathrm{Si}^{13} \mathrm{C}$ sample doped with deuterium were used as reference spectra for spectra 1) and 2), respectively); b) Details of infrared absorption spectra, measured at $10 \mathrm{~K}$ with a resolution $0.1 \mathrm{~cm}^{-1}$, on ${ }^{12} \mathrm{C}$-rich and ${ }^{13} \mathrm{C}-$ rich Fz-Si samples, which were doped with hydrogen, deuterium and $\mathrm{H}+\mathrm{D}$ mixture $(50 \%+50 \%)$. Multiplication factors for different parts of the spectra are indicated. All the samples were treated in $\mathrm{H}(\mathrm{D})$ gas ambient at $1350{ }^{\circ} \mathrm{C}$ for $30 \mathrm{~min}$ with a gas pressure of about $1.5 \mathrm{~atm}$.
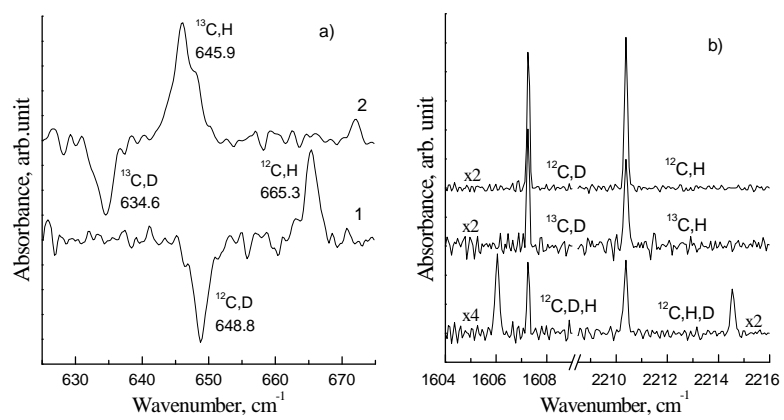

where $\mathrm{H}$ bonds to $\mathrm{Si}$ rather than $\mathrm{C}$ are given in ref. 5 while ref. 6 exemplifies the second defect type. In other cases, it is not clear which type is present ${ }^{7,8}$.

Recently, several local vibrational modes (LVMs) were observed in carbon-rich Si samples treated in a hydrogen ambient at high temperatures ${ }^{9-11}$. Some arise from a trigonal complex containing one carbon and two hydrogen atoms ${ }^{9,11}$. The LVMs of this defect, labeled $\left(\mathrm{C}-\mathrm{H}_{2}^{*}\right)_{2}$, 
TABLE I: Calculated (observed) LVMs, $\mathrm{cm}^{-1}$, for the $\left(\mathrm{C}-\mathrm{H}_{2}^{*}\right)_{2}$ trigonal defect $\left(\mathrm{CH}_{\mathrm{bc}} \mathrm{SiH}_{\mathrm{ab}}\right)$.

\begin{tabular}{|c|c|c|c|c|c|c|}
\hline $\begin{array}{l}\text { Suggested LVM } \\
\text { assignment }\end{array}$ & ${ }^{12} \mathrm{CH}_{\mathrm{bc}} \mathrm{SiH}_{\mathrm{ab}}$ & ${ }^{12} \mathrm{CD}_{\mathrm{bc}} \mathrm{SiH}_{\mathrm{ab}}$ & ${ }^{12} \mathrm{CH}_{\mathrm{bc}} \mathrm{SiD}_{\mathrm{ab}}$ & ${ }^{12} \mathrm{CD}_{\mathrm{bc}} \mathrm{SiD}_{\mathrm{ab}}$ & ${ }^{13} \mathrm{CH}_{\mathrm{bc}} \mathrm{SiH}_{\mathrm{ab}}$ & ${ }^{13} \mathrm{CD}_{\mathrm{bc}} \mathrm{SiD}_{\mathrm{ab}}$ \\
\hline$A_{1}(\mathrm{C}-\mathrm{H}$ stretch $)$ & 2736.3 & 2007.2 & 2736.3 & 2006.3 & $2728.7(2$ & 1995.3 \\
\hline$A_{1}$ (Si-H stretch) & $1923.3(1921.8)$ & 1922.5 & $1383.0(1400.3)$ & 1383.0 & 1923.3 (1921.8) & 1383.0 \\
\hline (C-H wag) & 896.5 & 708.6 & 895.9 & 709.1 & 892.7 & 694.6 \\
\hline (Si-H wag) & $812.3 \quad(792.0)$ & $(793.2)$ & $(571.8)$ & $(571.6)$ & $(792.0)$ & $(571.4)$ \\
\hline $\mathrm{Si}-\mathrm{H}$ wag overtone & $(1550.2)$ & & & & & \\
\hline$E \quad($ Si-C stretch $)$ & 628.6 & 581.3 & 628.6 & 581.3 & 612.7 & 576.1 \\
\hline
\end{tabular}

TABLE II: Calculated (observed) LVMs, $\mathrm{cm}^{-1}$, for the $\left(\mathrm{C}-\mathrm{H}_{2}^{*}\right)_{1}$ trigonal $\operatorname{defect}\left(\mathrm{SiH}_{\mathrm{bc}} \mathrm{CH}_{\mathrm{ab}}\right)$.

\begin{tabular}{cccccccccccccc}
\hline \hline $\begin{array}{l}\text { Suggested LVM } \\
\text { assignment }\end{array}$ & $\mathrm{SiH}_{\mathrm{bc}}{ }^{12} \mathrm{CH}_{\mathrm{ab}}$ & \multicolumn{2}{c}{$\mathrm{SiD}_{\mathrm{bc}}{ }^{12} \mathrm{CH}_{\mathrm{ab}}$} & $\mathrm{SiH}_{\mathrm{bc}}{ }^{12} \mathrm{CD}_{\mathrm{ab}}$ & $\mathrm{SiD}_{\mathrm{bc}}{ }^{12} \mathrm{CD}_{\mathrm{ab}}$ & $\mathrm{SiH}_{\mathrm{bc}}{ }^{13} \mathrm{CH}_{\mathrm{ab}}$ & $\mathrm{SiD}_{\mathrm{bc}}{ }^{13} \mathrm{CD}_{\mathrm{ab}}$ \\
\hline$A_{1}$ & (C-H stretch) & 2664.5 & $(-)$ & 2662.9 & $(-)$ & 1946.2 & $(-)$ & 1950.7 & $(-)$ & 2657.4 & $(-)$ & 1940.5 & $(-)$ \\
$A_{1}$ & (Si-H stretch) & 2172.3 & $(2210.4)$ & 1560.5 & $(1606.05)$ & 2177.8 & $(2214.5)$ & 1559.9 & $(1607.3)$ & 2172.2 & $(2210.4)$ & 1559.9 & $(1607.3)$ \\
$E$ & $($ C-H wag) & 1018.4 & $(-)$ & 1018.4 & $(-)$ & 750.7 & $(-)$ & 750.7 & $(-)$ & 1017.0 & $(-)$ & 743.4 & $(-)$ \\
$E$ & $($ Si-C) & 665.0 & $(665.3)$ & 665.0 & $(665.4)$ & 646.9 & $(649)$ & 646.9 & $(648.8)$ & 645.6 & $(645.85)$ & 633.4 & $(634.6)$ \\
$E$ & $($ Si-H wag) & 581.7 & $(-)$ & 536.3 & $(-)$ & 581.7 & $(-)$ & 536.3 & $(-)$ & 581.7 & $(-)$ & 536.2 & $(-)$ \\
\hline \hline
\end{tabular}

are given in Table I. Following previous theoretical results $^{12}$, it was suggested that this complex is a $\mathrm{H}_{2}^{*}$ defect trapped near $\mathrm{C}$. There are two possible trigonal forms of the center where the anti-bonding sited $\mathrm{H}$ is bonded to $\mathrm{Si}$ or $\mathrm{C}$ (Fig. 1). The observed modes are due to a defect somewhat more stable than $\mathrm{H}_{2}^{*}$, which disappears at $\lesssim 200{ }^{\circ} \mathrm{C}^{3,13}$, as the modes are observable after anneals up to $\sim 400{ }^{\circ} \mathrm{C}^{9,11}$. We show in the present work that there is another set of LVM absorption lines, which is related to the other form of $\mathrm{C}-\mathrm{H}_{2}^{*}$ center, labeled (C$\left.\mathrm{H}_{2}^{*}\right)_{1}$. These assignments are based on the analyses of shifts and splitting of the LVMs resulting from ${ }^{13} \mathrm{C}$ and $\mathrm{D}$ isotopic substitution as well as from uniaxial stress and comparison of the results with ab initio modeling.

\section{EXPERIMENTAL AND THEORETICAL DETAILS}

Samples for this study were prepared from lightlydoped $n$-type and $p$-type float-zone-grown Si crystals with different carbon concentrations in the range (1.5$3.0) \times 10^{17} \mathrm{~cm}^{-3}$. A few samples were prepared from a crystal enriched with ${ }^{13} \mathrm{C}$ isotopes to about $8 \times 10^{17} \mathrm{~cm}^{-3}$. Hydrogen and/or deuterium was introduced by a heat treatment at $1250-1350^{\circ} \mathrm{C}$ for $30 \mathrm{~min}$ or $1 \mathrm{~h}$ in a $\mathrm{H}_{2}\left(\mathrm{D}_{2}\right)$ gas ambient at a gas pressure of about 1.0 or 1.5 atm., followed by a quench. The isochronal annealing was carried out in an argon atmosphere in temperature steps of $25^{\circ} \mathrm{C}$ in the range of $100-450^{\circ} \mathrm{C}$, for $30 \mathrm{~min}$ at each temperature. The thickness of the samples was in most cases about $6 \mathrm{~mm}$. The samples used for the uniaxial stress measurements had dimensions $10 \times 3 \times 2 \mathrm{~mm}^{3}$. Optical
FIG. 3: The isochronal annealing temperature dependence of the integrated absorption intensity of the bands at 665.3 and $2210.4 \mathrm{~cm}^{-1}$ in a ${ }^{12} \mathrm{C}$-rich FZ-Si sample which was treated in $\mathrm{H}_{2}$ gas ambient at $1350{ }^{\circ} \mathrm{C}$ for $30 \mathrm{~min}$. IR absorption measurements were carried out at $10 \mathrm{~K}$ with a resolution $0.5 \mathrm{~cm}^{-1}$.

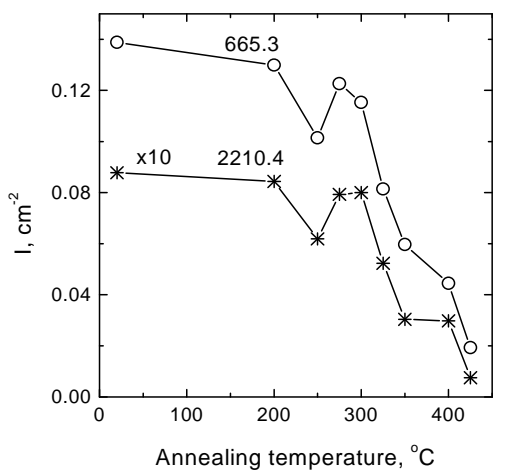

absorption spectra were measured by Fourier transform infrared (FT-IR) spectrometers at $\sim 10 \mathrm{~K}$. The spectral resolution varied from 0.1 to $0.5 \mathrm{~cm}^{-1}$.

The properties of $\mathrm{C}-\mathrm{H}_{2}^{*}$ defects in silicon, were investigated by a local density-functional technique as implemented in the AIMPRO code ${ }^{14}$. The defects were inserted into 64 atom supercells and a $2^{3}$ Monkhorst-Pack $k$ point sampling scheme used to integrate over the band structure $^{15}$. The basis consisted of independent $s$ - and $p$-Gaussian orbitals, with four different exponents, sited at each $\mathrm{Si}$ atom, four at the carbon atom, and three at the $\mathrm{H}$ atom. In addition, a single set of $s$ - and $p$-Gaussian functions was placed between every neighboring pair of 
FIG. 4: High-resolution infrared absorption spectrum showing silicon isotope satellites of the $2210.4 \mathrm{~cm}^{-1}$ line in a $\mathrm{Si}$ :C crystal doped with hydrogen.

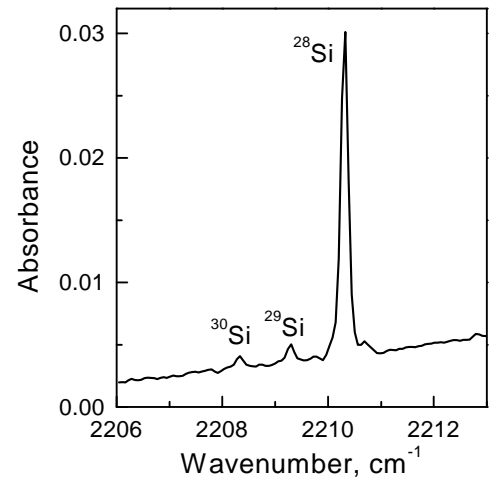

atoms. The Hartree and Perdew-Zunger ${ }^{16}$ exchangecorrelation energies were calculated using a plane-wave intermediate fit with an energy cut-off of 200 Ry. All atoms were allowed to relax by a conjugate gradient method. The second derivatives of the energy were found for the atoms of the defects and their immediate neighbors, allowing vibrational modes to be calculated from the dynamical matrix, with additional entries in the matrix constructed from a Musgrove-Pople potential (further details are given in Ref 17).

\section{RESULTS}

Among the many sharp absorption lines observed in the frequency ranges 660-690, 790-820, 1920-1960, 21202230 , and $2680-2950 \mathrm{~cm}^{-1} 9-11$ lines at $2210.4 \mathrm{~cm}^{-1}$ and $665.3 \mathrm{~cm}^{-1}$ are of particular interest in the present work (Fig. 2). A clear linear correlation was found between the intensities of these lines in different samples and the lines were found to have an identical annealing behavior as illustrated in Fig. 3. This suggests that they originate from the same defect. The positions of the lines of this complex, labeled $\left(\mathrm{C}-\mathrm{H}_{2}^{*}\right)_{1}$, in Si crystals containing different $\mathrm{C}$ and $\mathrm{H}$ isotopes are given in Table II.

The shift of the $665.3 \mathrm{~cm}^{-1}$ line with ${ }^{13} \mathrm{C}$ and $\mathrm{D}$ (Fig. 2a) demonstrates that the defect contains one $\mathrm{C}$ and at least one hydrogen atom. Inspection of the shifts of the $2210.4 \mathrm{~cm}^{-1}$ line, as well as its splitting in the mixed $\mathrm{H}+\mathrm{D}$ case (Fig. $2 \mathrm{~b}$ ), shows that there should be two weakly interacting $\mathrm{H}$ atoms, one of them being attached to a silicon atom. This is evidenced by the observation of silicon isotope shifts for the $2210.4 \mathrm{~cm}^{-1}$ line. Fig. 4 shows weak satellite lines on the low-energy side of the main line due to the presence of the naturally occurring isotopes ${ }^{29} \mathrm{Si}$ (4.7\% abundant) and ${ }^{30} \mathrm{Si}(3.0 \%)$.

Figures 5 and 6 show the effect of uniaxial stress on the $2210.4 \mathrm{~cm}^{-1}$ mode. The number of lines and their relative intensities for each orientation and light polar- ization are consistent with a non-degenerate vibrational mode $\left(A_{1}\right)$ of a trigonal center $\left(C_{3 v} \text { point group }\right)^{18,19}$. The values of the $A$ piezospectroscopic tensor components were found to be $A_{11}=2.70 \pm 0.1 \mathrm{~cm}^{-1} \mathrm{GPa}^{-1}$ and $A_{22}=4.15 \pm 0.1 \mathrm{~cm}^{-1} \mathrm{GPa}^{-1}$.

All combinations of pairs of hydrogen atoms at bondcenter and anti-bonding sites within one and two neighboring sites of substitutional carbon were structurally relaxed. Two degenerate structures with $C_{3 v}$ symmetry were found to possess the lowest energy by at least $\gtrsim 0.4 \mathrm{eV}$. These structures are similar to the $\mathrm{H}_{2}^{*}$ defect $^{3}$ and are shown in Fig. 1. The relative binding energy of the two degenerate $\mathrm{C}-\mathrm{H}_{2}^{*}$ defects with respect to separated $\mathrm{C}_{\mathrm{s}}$ and $\mathrm{H}_{2}$ was found to be $0.79 \mathrm{eV}\left(\mathrm{H}_{2}\right.$ is considered to be slightly lower in energy than $\mathrm{H}_{2}^{* 20}$ ). The calculated LVMs are given in Tables I and II. The calculated Si-H stretch mode in $\mathrm{SiH}_{\mathrm{bc}} \mathrm{CH}_{\mathrm{ab}}$ (Fig. 1a) at $2172 \mathrm{~cm}^{-1}$ is close to the observed mode at $2210.4 \mathrm{~cm}^{-1}$. There are undetected $\mathrm{C}-\mathrm{H}$ stretch and bend modes at 2664.5 and $1018.4 \mathrm{~cm}^{-1}$ respectively. We assign the observed mode at $665.3 \mathrm{~cm}^{-1}$ to the $E(\mathrm{C}-\mathrm{Si})$ mode at the same frequency. The isotopic shifts are in good agreement with the experimental ones. Accordingly, we assign the (C$\left.\mathrm{H}_{2}^{*}\right)_{1}$ defect to $\mathrm{SiH}_{\mathrm{bc}} \mathrm{CH}_{\mathrm{ab}}$.

We turn now to the previously reported modes of (C$\left.\mathrm{H}_{2}^{*}\right)_{2}{ }^{9}$. These are in good agreement with the calculated modes of $\mathrm{CH}_{\mathrm{bc}} \mathrm{SiH}_{\mathrm{ab}}$ shown in Fig. 1b. In particular, the $\mathrm{C}-\mathrm{H}$ and $\mathrm{Si}-\mathrm{H}$ stretch modes observed at 2752 and $1922 \mathrm{~cm}^{-1}$ are close to the calculated ones at 2736 and $1923 \mathrm{~cm}^{-1}$. The Si-H wag mode at 792 is close to the calculated one at $812 \mathrm{~cm}^{-1}$. Similarly, there is good agreement with the isotopic shifts. Accordingly, we assign the $\left(\mathrm{C}-\mathrm{H}_{2}^{*}\right)_{2}$ defect to $\mathrm{CH}_{\mathrm{bc}} \mathrm{SiH}_{\mathrm{ab}}$.

Finally, for completeness, the stress-energy $B$-tensor for both forms of $\mathrm{H}_{2}^{*}$ were calculated. The tensors are evaluated directly by first relaxing the volume of the cubic cell and then calculating $\partial E / \partial \epsilon_{i j}$ with Cartesian axes, where $\epsilon_{i j}$ is the strain ${ }^{14}$. For trigonal defects the tensor has principal values $\frac{1}{2} B_{11}=-B_{22}=-B_{33}$ with the principle directions $\left\langle\begin{array}{llll}1 & 1 & 1\end{array}\right\rangle$ (along the $C_{3}$ axis), $\left\langle\begin{array}{lll}1 & \overline{1} & 0\end{array}\right)$ and $\left\langle\begin{array}{lll}1 & 1 & \overline{2}\end{array}\right\rangle$. The values of $B_{11}$ for $\mathrm{SiH}_{\mathrm{bc}} \mathrm{CH}_{\mathrm{ab}}$ and $\mathrm{CH}_{\mathrm{bc}} \mathrm{SiH}_{\mathrm{ab}}$ were found to be 7.69 and $11.15 \mathrm{eV}$ per unit strain. The fractional volume change for the defects in a 64 atom cubic cell were found to be $0.2 \%$ and $0.3 \%$ respectively, i.e., $\Delta V / V_{0}=64 \times 0.2 \%$. So the volume change caused by the defect is just $0.1 \times V_{0}$ where $V_{0}$ is volume of Si atom (defined as $a_{0}^{3} / 8$ ).

The $\mathrm{CH}_{2}^{*}$ defects are very stable. The binding energy of a hydrogen molecule to substitutional carbon in the $\mathrm{CH}_{2}^{*}$ defect is $\sim 0.8 \mathrm{eV}$. This binding energy accounts for the stability of the defects which survive up to $400^{\circ} \mathrm{C}$, in contrast to isolated $\mathrm{H}_{2}^{*}$ which anneals at $\lesssim 200^{\circ} \mathrm{C}^{3,13}$. Further hydrogen atoms can also be bound at or by carbon, leading to defects such as $\mathrm{C}_{\mathrm{s}}\left(\mathrm{H}_{2}^{*}\right)_{2}$. One of the $C_{2 v}$ forms of this defect, consisting of two $\mathrm{H}_{2}^{*}$ units both involving a shared carbon atom as $\mathrm{C}_{\mathrm{s}}\left(\mathrm{H}_{b c}\right)_{2} \cdots\left(\mathrm{SiH}_{a b}\right)_{2}$, is bound by $1.5 \mathrm{eV}$ compared to $\mathrm{C}_{\mathrm{s}}+2 \times \mathrm{H}_{2}$. This form of aggregation is distinct from the hydrogen platelets cre- 
FIG. 5: Effect of stress, $\sigma$, on the $2210.4 \mathrm{~cm}^{-1}$ line in hydrogen-doped Si:C crystals. The stress direction and magnitude and the polarization vector, $\sigma$, for the incident light are given. The stick-bars show the fitted peak positions and relative intensities.
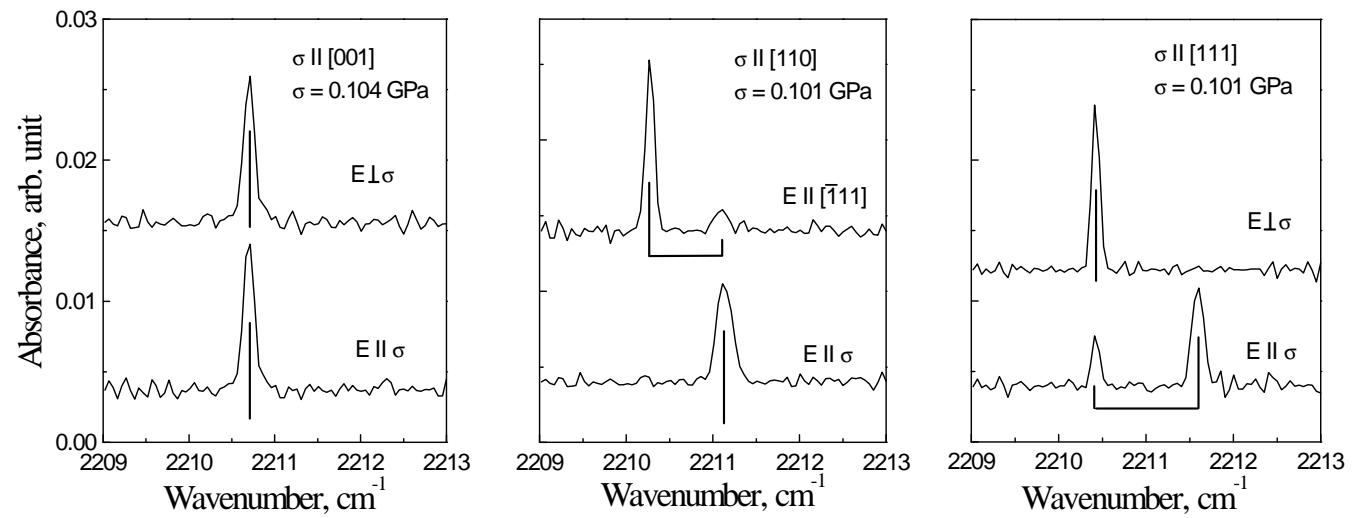

FIG. 6: The effect of uniaxial stress on the $2210.4 \mathrm{~cm}^{-1}$ mode. The stress direction and the polarization vector, E, for the incident light are indicated. The solid lines are the best-fit frequency shifts for a trigonal center with the following components of the piezospectroscopic tensor: $A_{11}=2.70 \mathrm{~cm}^{-1} \mathrm{GPa}^{-1}$ and $A_{22}=4.15 \mathrm{~cm}^{-1} \mathrm{GPa}^{-1}$.
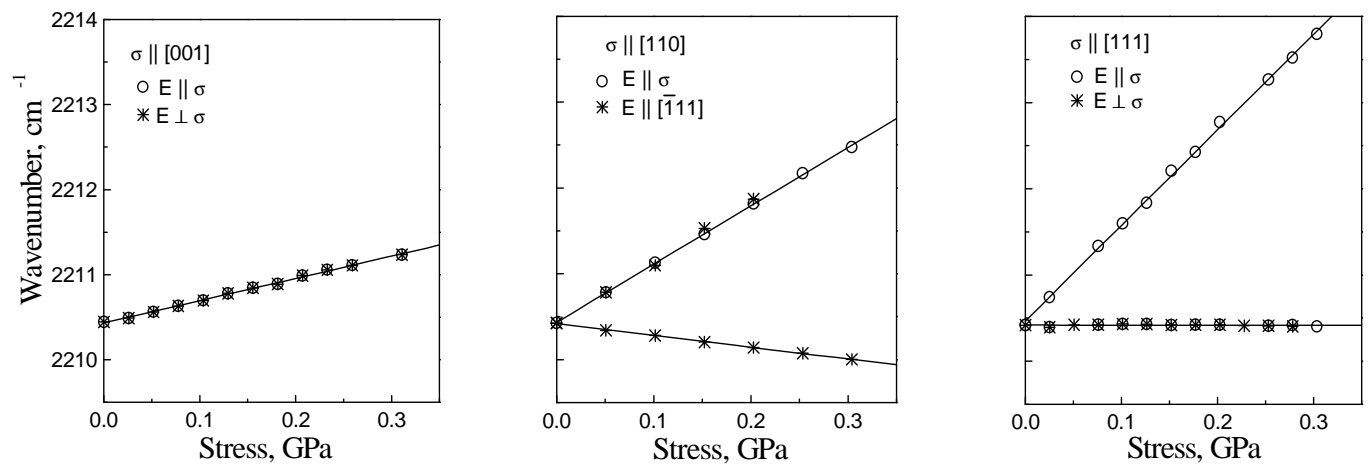

ated in plasma treated $\mathrm{Si}^{21}$, one form of which having been suggested to be due to sheets of $\mathrm{H}_{2}^{*}$ units in (111) planes $^{22,23}$.

\section{SUMMARY}

Two H-related defects have been investigated by local mode spectroscopy and $a b$ initio modeling. Unlike carbon lean material where no lines (except some traces of $\mathrm{H}_{2}^{*}$ ) are observed in the frequency ranges of $790-820$, 1920-2230 and 2680-2950 $\mathrm{cm}^{-1}$ after heat treatments at $1200-1350{ }^{\circ} \mathrm{C}$ in $\mathrm{H}_{2}$ gas, two strong LVM lines are observed at 1921.8 and $2210.4 \mathrm{~cm}^{-1}$ in carbon rich material treated with hydrogen. These lines are identified with Si$\mathrm{H}$ stretch modes of two forms of $\mathrm{C}-\mathrm{H}_{2}^{*}$ defects where $\mathrm{H}$ lies antibonded to $\mathrm{Si}$ and $\mathrm{C}$ atoms respectively. Several other modes are observed in each defect and related to partic- ular atomic displacements. These defects are formed by breaking lattice bonds and are $\sim 0.8 \mathrm{eV}$ more stable than a hydrogen molecule near a carbon impurity.

A pair of molecules can also be trapped by a carbon impurity leading to bond breaking and the formation of two $\mathrm{H}_{2}^{*}$ species. This defect possesses $C_{2 v}$ symmetry. Thus, it does not appear that the presence of carbon favors (111) platelet growth.

\section{Acknowledgments}

The Engineering and Physical Science Research Council (EPSRC) UK are thanked for their financial support. We also acknowledge financial support from TFR and KVA in Sweden and from the Fund for Fundamental Research of the Republic of Belarus. 
* Electronic address: B.Hourahine@exeter.ac.uk

$\dagger$ Permanent address : Institute of Solid State and Semiconductor Physics, Minsk 220072, Belarus

1 S. Pearton, M. Stavola, and J. W. Corbett, Acta Metall. 4, 332 (1992).

2 G. Davies and R. C. Newman, Handbook on semiconductors (Elsevier, Amsterdam, 1994), vol. 3, p. 1557.

3 J. D. Holbech, B. Bech Nielsen, R. Jones, P. Sitch, and S. Öberg, Phys. Rev. Lett. 71, 875 (1993).

4 A. G. Gaydon, Dissociation energies and spectra of diatomic molecules (Chapman and Hall, London, 1968), 3rd ed.

${ }^{5}$ L. Hoffmann, E. V. Lavrov, B. Bech Nielsen, B. Hourahine, R. Jones, S. Öberg, and P. R. Briddon, Phys. Rev. B 61, 16659 (2000).

${ }^{6}$ E. V. Lavrov, B. Bech Nielsen, B. Hourahine, R. Jones, S. Öberg, and P. R. Briddon, Phys. Rev. B 62, 12859 (2000).

7 A. Endrös, Phys. Rev. Lett. 63, 70 (1989).

8 Y. Kamiura, K. Fukuda, Y. Yamashita, and T. Ishiyama, Defect and Diffusion Forum 183, 25 (2000).

9 V. P. Markevich, L. I. Murin, J. Hermansson, M. Kleverman, J. L. Lindström, N. Fukata, and M. Suezawa, Physica B 302-303, 220 (2001).

10 N. Fukata and M. Suezawa, J. Appl. Phys. 86, 1848 (1999).

11 B. Hourahine, R. Jones, S. Öberg, P. R. Briddon, V. P.
Markevich, R. C. Newman, J. Hermansson, M. Kleverman, J. L. Lindstrom, L. I. Murin, N. Fukata, M. Suezawa, Physica B In press (2001).

12 P. Leary, R. Jones, and S. Öberg, Phys. Rev. B 57, 3887 (1998).

13 M. Suezawa, J. Appl. Phys. 86, 4865 (1999).

14 J. Coutinho, R. Jones, P. R. Briddon, and S. Öberg, Phys. Rev. B 62, 10824 (2000).

15 H. J. Monkhorst and J. D. Pack, Phys. Rev. B 13, 5188 (1976).

16 J. P. Perdew and A. Zunger, Phys. Rev. B 23, 5048 (1981).

17 R. Jones and P. R. Briddon, The ab initio cluster method and the dynamics of defects in semiconductors (Academic Press, Boston, 1998), vol. 51A of Semiconductors and Semimetals, chap. 6.

18 A. A. Kaplyanskii, Opt. Spectrosc. 16, 329 (1964).

19 A. A. Kaplyanskii, Opt. Spectrosc. 16, 602 (1964).

20 C. G. Van de Walle, Phys. Rev. B 49, 4579 (1994)

21 N. M. Johnson, F. A. Ponce, R. A. Street, and R. J. Nemanich, Phys. Rev. B 35, 4166 (1987).

22 S. B. Zhang and W. B. Jackson, Phys. Rev. B 43, 12142 (1991).

${ }^{23}$ Y. S. Kim and K. J. Chang, Phys. Rev. Lett. 86, 1773 (2001). 